\title{
Uncertainty Determinants of Firm Investment
}

\author{
Christopher F Baum* \\ Boston College and DIW Berlin \\ Mustafa Caglayan \\ University of Sheffield \\ Oleksandr Talavera \\ DIW Berlin
}

April 18, 2007

\begin{abstract}
We investigate the impact of measures of uncertainty on firms' capital investment behavior using a panel of U.S. firms. Increases in firmspecific and $C A P M$-based measures have a significant negative effect on investment spending, while market-based uncertainty has a positive impact.
\end{abstract}

Keywords: capital investment, asymmetric information, financial frictions, uncertainty, CAPM

JEL: E22, D81, C23

*Corresponding author: Christopher F Baum, Department of Economics, Boston College, Chestnut Hill, MA 02467 USA, Tel: 617-552-3673, fax 617-552-2308, e-mail: baum@bc.edu. 


\section{Introduction}

Researchers have expended considerable effort in trying to understand the linkages between uncertainty and investment behavior at both firm-specific and aggregate levels. ${ }^{1}$

In this paper, we consider the effects of three different forms of uncertainty on firms' investment behavior: Own uncertainty, derived from firms' stock returns; Market uncertainty, driven by S\&P 500 index returns, and the relations between intrinsic and extrinsic uncertainty. To capture the latter effect, we introduce a covariance term (our CAPM-based risk measure) and allow the data to determine the differential impact of each of these components on firms' investment.

Early research, using risk measures constructed from stock return data, has shown that uncertainty exerts a strong negative effect on investment. However, researchers also find that the effects of uncertainty on investment generally disappear (e.g., Leahy and Whited (1996), p. 74) when Tobin's $Q$ is introduced into the empirical model. In contrast, we show that firm-specific and macroeconomic uncertainty along with their interaction (CAPM based uncertainty) have a significant effect on investment even in the presence of $Q$, cash flow and the debt-to-capital ratio.

Below we present our empirical findings. In our analysis we implement a standard investment model which incorporates various measures of uncertainty while controlling for firm financial characteristics.

\footnotetext{
${ }^{1}$ See, for example, Brainard, Shoven and Weiss (1980), Ghosal and Loungani (1996), Guiso and Parigi (1999), Beaudry, Caglayan and Schiantarelli (2001), Calcagnini and Saltari (2001) and Henley, Carruth and Dickerson (2003).
} 


\section{Empirical findings}

\subsection{Data}

The estimation sample consists of an unbalanced panel of manufacturing firms for the 1984 to 2003 period drawn from Standard and Poor's Industrial Annual COMPUSTAT database. There are 9,895 firm-years for which the replacement value of the real capital stock may be imputed by the method of Salinger and Summers (1983). A number of sample selection criteria are then applied. We only consider firms who have not undergone substantial changes in their composition during the sample period (e.g., participation in a merger, acquisition or substantial divestment). As these phenomena are not observable in the data, we calculate the growth rate of each firm's real total assets, and trim the annual distribution of this growth rate by the 5th and 95th percentiles to remove firms exhibiting substantial changes in their scale. Values of the investment-to-capital, cash flow-to-capital, debt-tocapital ratios and Tobin's $Q$ outside the $5-95$ th percentile range are judged implausible. Firms in clear financial distress or those facing substantial liquidity constraints are excluded. One per cent from either end of the annual returns distribution was trimmed. The final data set contains 4,028 firm-years pertaining to 360 firms with complete data for all variables used in the analysis. ${ }^{2}$

\footnotetext{
${ }^{2}$ Empirical results drawn from the full sample yielded qualitatively similar findings; the screened data were used to reduce the potential impact of outliers upon the parameter estimates.
} 


\subsection{Generating volatility measures from daily data}

We utilize daily stock returns and market index returns to compute intrinsic and extrinsic uncertainty via a method based on Merton (1980) from the intra-annual variations in stock returns and aggregate financial market series. This approach provides a more representative measure of the perceived volatility. It avoids such potential problems as high shock persistence when moving average representations are used, and low correlation in volatility when $\mathrm{ARCH} / \mathrm{GARCH}$ models are applied to quantify volatility in low-frequency series. In that respect, our study improves upon much of the literature in its method of using high-frequency data to quantify volatility evaluated at a lower frequency. ${ }^{3,4}$

In order to employ the Merton methodology, we must compute the intraannual volatility of the series from daily data. ${ }^{5}$ We first take the squared first difference of the daily changes in returns (after dividing by the square root of the number of days intervening), which is later defined as the daily contribution to annual volatility:

$$
\varsigma_{t}^{d}=\left(100 \frac{\Delta x_{t}}{\sqrt{\Delta \phi_{t}}}\right)^{2}
$$

where the denominator expresses the effect of calendar time elapsing between observations on the $x$ process. If data were generated on every calendar day, $\Delta \phi_{t}=1, \forall t$, but given that data are not available on weekends and holidays,

\footnotetext{
${ }^{3}$ Leahy and Whited (1996), Bloom, Bond and Van Reenen (2001), Bond and Cummins (2004) have also utilized daily stock returns to compute firm-level uncertainty. However, the methodology they used to generate a proxy for uncertainty was different from ours.

${ }^{4}$ See Baum, Caglayan and Ozkan (2004) for a more detailed discussion of the Merton procedure along with its merits.

${ }^{5}$ The daily returns series are taken from CRSP. For the market index returns, we use returns on the S\&P 500 index, inclusive of dividends.
} 
$\Delta \phi_{t} \in(1,5)$. The estimated annual volatility of the return series is defined as $\Phi_{t}\left[x_{t}\right]=\sqrt{\sum_{t=1}^{T} \varsigma_{t}^{d}}$ where the time index for $\Phi_{t}\left[x_{t}\right]$ is at the annual frequency.

\subsection{Descriptive statistics}

Descriptive statistics for the firm-year observations entering the analysis are presented in Table $1 .^{6}$ The lagged real replacement value of the capital stock $(\mathrm{K})$ is used as a deflator. The average (median) investment rate for our sample is about $10.2 \%(8.6 \%)$ and that of $Q$ is about $2.37(1.76)$. These values of $Q$ are comparable to those in Leahy and Whited (1996), Table 1. The last three lines, labeled as $\eta_{t}, \varepsilon_{t}$ and $\nu_{t}$ give the basic statistics for the constructed measures of uncertainty obtained from firm stock returns, $\mathrm{S} \& \mathrm{P}$ index returns and the covariance between firm and market returns, respectively. In the estimated model, these measures enter in lagged form to reflect the manager's information set at time $t .^{7}$

\subsection{The link between uncertainty and capital investment}

We employ the dynamic panel data (DPD) approach developed by Arellano and Bond (1991), as implemented in Stata by Roodman (2007). All models are estimated in first difference terms to eliminate the fixed effects using the

\footnotetext{
${ }^{6}$ The number of firm-years used in the estimation is reduced to 2,647 as deflation by the lagged capital stock and the use of the lagged investment rate leads to the loss of two years per firm.

${ }^{7}$ The use of lagged uncertainty measures is motivated by the fact that actual investment at time $t$ is affected by observed uncertainty in the environment. Our uncertainty measures are based on stock prices, themselves forward-looking measures of profitability. In that sense recently observed uncertainty in an efficient markets setting represents a forecast of uncertainty over the investment horizon.
} 
one-step GMM estimator.

Column 1 of Table 2 presents a standard investment model which contains Tobin's $Q$, the lagged Cash flow/K ratio and the lagged Debt/K ratio along with the lagged dependent variable as a benchmark. The signs of the lagged cash flow ratio, Tobin's $Q$ and lagged investment are positive and significant while the sign of the lagged Debt/K ratio is negative and insignificant. The $J$ statistic (and the corresponding $p$-value) is the Hansen-Sargan test statistic and it indicates that the test for overidentifying restrictions is satisfactory (as it is in all reported estimates). Furthermore, we reject the presence of second-order autocorrelation $(A R(2))$ validating the use of suitably lagged endogenous variables as instruments. ${ }^{8}$

Given satisfactory benchmark results, we introduce our measures of lagged intrinsic and extrinsic uncertainty. Column two provides our results when we introduce the lagged Own (intrinsic) uncertainty measure, $\eta_{t}$, into our basic framework. The magnitude and significance of the coefficients of Tobin's $Q$, the lagged Cash flow/K ratio, the lagged Debt/K ratio and the lagged investment rate variable are not altered. The coefficient for Own uncertainty $\left(\eta_{t}\right)$ is negative and significant at the $1 \%$ level. This is an interesting finding as Leahy and Whited (1996) report that uncertainty affects the investment behavior through $Q$ (in their analysis the coefficient on their proxy for uncertainty becomes insignificant with the introduction of $Q$ ). In our case, even in the presence of $Q$, intrinsic uncertainty is significant. ${ }^{9}$

\footnotetext{
${ }^{8}$ The second through fourth lags of the investment rate, Tobin's $Q$, the Cash flow/K ratio, the Debt/K ratio, the Sales/K ratio and Sales are employed as GMM instruments. In the models including lagged uncertainty measures, second through fourth lags of those measures were also included as GMM instruments.

${ }^{9}$ Our findings cannot be directly contrasted with those of Leahy and Whited (1996) as our uncertainty measures are based on a very different methodology. Furthermore, the
} 
We then add Market uncertainty, $\varepsilon_{t}$, to the original equation (excluding the intrinsic measure) in column three. Its coefficient is almost identical in magnitude to that of Own uncertainty, negative and significant. We consider a model in which both Own and Market measures are included in column four. When entered jointly, although the coefficient of the Market measure $\left(\varepsilon_{t}\right)$ becomes positive, it is not significantly different from zero while that of Own uncertainty $\left(\eta_{t}\right)$ is still negative and significant. This shows that firmspecific uncertainty has a more prominent impact on investment spending than does market-based uncertainty.

To evaluate possible interactions between the two forms of uncertainty, we introduce them along with our measure of CAPM-based uncertainty: $\operatorname{Cov}\left(O w n_{r e t}, M k t_{r e t}\right)_{i, t-1}$, denoted $\nu_{t}$. The results associated with this model are presented in column five. This model yields interesting findings. The coefficient on Own uncertainty $\left(\eta_{t}\right)$ is once again negative and significant, but that of Market uncertainty $\left(\varepsilon_{t}\right)$ is now positive and significant at the $5 \%$ level. We also observe that the CAPM-based uncertainty measure $\left(\nu_{t}\right)$ is negative and significant, as theory would suggest. In the last three rows of the table, we report the elasticities of the investment rate with respect to the uncertainty measures. The elasticity for Own uncertainty is in the range $(-0.105,-0.117)$, a quite substantial magnitude in economic terms. The elasticities for Market and $C A P M$ uncertainty are smaller in absolute value but represent non-trivial impacts on the rate of investment, particularly in a period when changes in uncertainty may be quite substantial due to stockmarket volatility.

These results are quite interesting supporting the implications of CAPM

two models are different: our model includes the lagged investment rate, which theirs excludes, and their model includes time dummies. 
theory and stands in clear contrast to the findings reported by Leahy and Whited (1996). It also appears that when both market uncertainty and the CAPM uncertainty measure are included in the model, the level of market uncertainty serves as a moderating influence on the effects of the CAPM uncertainty measure. It is perhaps possible that the positive coefficient on market uncertainty is capturing the existence of a real option for managers to invest so that their firm can possess a greater opportunity to expand its presence in that market.

\section{Conclusions}

In this paper we investigate the empirical linkages between firms' capital investment behavior and three forms of uncertainty. Previous research has found that firm-specific or macro-based measures of uncertainty are insignificant in the presence of $Q$ and that CAPM-based uncertainty measures have no significant impact on investment behavior. In contrast, we show that Own uncertainty is operative and has a negative impact on investment in a model incorporating a measure of Tobin's $Q$, and our measure of CAPMbased uncertainty has a negative effect on investment while Market uncertainty has a positive impact. An important lesson to be learned from this paper is that the effects of uncertainty on investment may be sensitive to model specification, choice of sample and design of uncertainty proxies. Given that managers facing capital investment decisions may use different methods to predict uncertainty, our model and the simplicity of its uncertainty proxy may be appealing. 


\section{References}

Arellano, M. and Bond, S. (1991), 'Some tests of specification for panel data: Monte Carlo evidence and an application to employment equations', Review of Economic Studies 58(2), 277-97.

Baum, C. F., Caglayan, M. and Ozkan, N. (2004), 'Nonlinear effects of exchange rate volatility on the volume of bilateral exports', Journal of Applied Econometrics 19, 1-23.

Beaudry, P., Caglayan, M. and Schiantarelli, F. (2001), 'Monetary instability, the predictability of prices and the allocation of investment: An empirical investigation using UK panel data', American Economic Review 91(3), 648-662.

Bloom, N., Bond, S. and Van Reenen, J. (2001), The dynamics of investment under uncertainty, Working Papers WP01/5, Institute for Fiscal Studies.

Bond, S. R. and Cummins, J. G. (2004), Uncertainty and investment: An empirical investigation using data on analysts' profits forecasts, Finance and Economics Discussion Series 2004-20, Board of Governors of the Federal Reserve System.

Brainard, W., Shoven, J. and Weiss, L. (1980), 'The financial valuation of the return to capital', Brookings Papers on Economic Activity 2, 453502.

Calcagnini, G. and Saltari, E. (2001), 'Investment and uncertainty: Is there a potential role for a common European policy?', Economics Letters 72(1), 61-65. 
Ghosal, V. and Loungani, P. (1996), 'Product market competition and the impact of price uncertainty on investment: Some evidence from US manufacturing industries', Journal of Industrial Economics 44, 21728.

Guiso, L. and Parigi, G. (1999), 'Investment and demand uncertainty', Quarterly Journal of Economics 114, 185-227.

Henley, A., Carruth, A. and Dickerson, A. (2003), 'Industry-wide versus firm-specific uncertainty and investment: British company panel data evidence', Economics Letters 78(1), 87-92.

Leahy, J. V. and Whited, T. M. (1996), 'The effect of uncertainty on investment: Some stylized facts', Journal of Money, Credit and Banking 28(1), 64-83.

Merton, R. C. (1980), 'On estimating the expected return on the market: An exploratory investigation', Journal of Financial Economics 8, 323-61.

Roodman, D. M. (2007), 'XTABOND2: Stata module to extend xtabond dynamic panel data estimator', available at: http://ideas.repec.org/c/boc/bocode/s435901.html. Accessed 14 March 2007.

Salinger, M. and Summers, L. (1983), Tax reform and corporate investment: A microeconomic simulation study, in M. Feldstein, ed., 'Behavioral Simulation Models in Tax Policy Analysis', University of Chicago Press. 
Table 1: Descriptive statistics

\begin{tabular}{lrrrrr}
\hline \hline & $\mathrm{p} 25$ & $\mathrm{p} 50$ & $\mathrm{p} 75$ & mean & $\mathrm{sd}$ \\
\hline Investment rate & 0.0545 & 0.0861 & 0.1304 & 0.1017 & 0.0631 \\
Tobin's Q & 0.9387 & 1.7557 & 3.0788 & 2.3717 & 2.0132 \\
Cash flow/K ratio & 0.1071 & 0.1711 & 0.2701 & 0.2111 & 0.1540 \\
Debt/K ratio & 0.1853 & 0.3287 & 0.6079 & 0.5295 & 0.7041 \\
$\eta_{t}$ & 0.4618 & 0.7067 & 1.0890 & 0.8489 & 0.5547 \\
$\varepsilon_{t}$ & 0.0875 & 0.1842 & 0.2953 & 0.2101 & 0.1404 \\
$\nu_{t}$ & 0.0217 & 0.0456 & 0.0866 & 0.0620 & 0.0567 \\
Firm-years & 4,028 & & & & \\
\hline \hline
\end{tabular}

Notes: $p 25, p 50, p 75$ are the quartiles of the variables, while $s d$ are their standard deviations. The investment rate is the ratio of investment to the lagged replacement value of the capital stock, $\mathrm{K}$. The $\eta_{t}$ term is a measure of intrinsic uncertainty, while $\varepsilon_{t}$ refers to extrinsic uncertainty and $\nu_{t}$ is the CAPM-based risk measure. 
Table 2: Robust GMM estimates of the investment rate

\begin{tabular}{lrrrrr} 
& $(1)$ & $(2)$ & $(3)$ & $(4)$ & $(5)$ \\
\hline Investment rate $t-1$ & $0.306^{* * *}$ & $0.305^{* * *}$ & $0.330^{* * *}$ & $0.338^{* * *}$ & $0.334^{* * *}$ \\
& $(0.054)$ & $(0.061)$ & $(0.048)$ & $(0.046)$ & $(0.043)$ \\
Tobin's Q $t$ & $0.005^{* *}$ & $0.008^{* * *}$ & $0.006^{* *}$ & $0.006^{* *}$ & $0.007^{* * *}$ \\
& $(0.003)$ & $(0.003)$ & $(0.002)$ & $(0.003)$ & $(0.003)$ \\
Cash flow/K ratio & $0.184^{* * *}$ & $0.161^{* * *}$ & $0.180^{* * *}$ & $0.190^{* * *}$ & $0.183^{* * *}$ \\
& $(0.033)$ & $(0.032)$ & $(0.031)$ & $(0.031)$ & $(0.030)$ \\
Debt/K ratio $t-1$ & -0.009 & -0.006 & -0.007 & -0.008 & -0.010 \\
& $(0.008)$ & $(0.007)$ & $(0.007)$ & $(0.008)$ & $(0.008)$ \\
$\eta_{t-1}$ & & $-0.014^{* * *}$ & & $-0.014^{* *}$ & $-0.013^{* *}$ \\
& & $(0.004)$ & & $(0.006)$ & $(0.006)$ \\
$\varepsilon_{t-1}$ & & & $-0.015^{* *}$ & 0.006 & $0.036^{* *}$ \\
& & & $(0.007)$ & $(0.011)$ & $(0.017)$ \\
$\nu_{t-1}$ & & & & & $-0.107^{* * *}$ \\
& & & & & $(0.037)$ \\
\hline Firm-years & 2,647 & 2,647 & 2,647 & 2,647 & 2,647 \\
Firms & 360 & 360 & 360 & 360 & 360 \\
$J$ & 296.683 & 301.313 & 325.924 & 340.632 & 343.319 \\
$J$ pvalue & 0.176 & 0.256 & 0.383 & 0.465 & 0.942 \\
AR $(2)$ & -1.056 & -1.043 & -0.869 & -0.853 & -0.957 \\
AR $(2)$ pvalue & 0.291 & 0.297 & 0.385 & 0.394 & 0.338 \\
Elas. $\eta$ & & -0.117 & & -0.115 & -0.105 \\
Elas. $\varepsilon$ & & & -0.033 & 0.013 & 0.076 \\
Elas. $\nu$ & & & & & -0.067 \\
\hline & & & & &
\end{tabular}

$$
p<0.10,{ }^{* *} p<0.05,{ }^{* * *} p<0.01
$$

Notes: All estimates are generated by Arellano-Bond one-step difference GMM. The instrument set is described in the text. $J$ is the Hansen-Sargan test of overidentifying restrictions, while $A R(2)$ is the Arellano-Bond test of second order autocorrelation in the errors. The $\eta$ term is a measure of intrinsic uncertainty, while $\varepsilon$ refers to extrinsic uncertainty and $\nu$ is the CAPM-based risk measure. 